\title{
Primary pulmonary intravascular large B-cell lymphoma: A report of three cases and literature review
}

\author{
YINGWEI ZHANG $^{1 *}$, LINTAO BI ${ }^{2 *}$, YUYING QIU ${ }^{1}$, TINGTING ZHAO $^{1}$, MENGSHU CAO $^{1}$, \\ JINGJING DING ${ }^{1}$, FANQING MENG $^{3}$ and HOURONG CAI ${ }^{1}$
}

\author{
${ }^{1}$ Department of Respiratory Diseases, Nanjing Drum Tower Hospital Affiliated to Medical School of Nanjing University, \\ Nanjing, Jiangsu 210008; ${ }^{2}$ Department of Oncology and Hematology, China-Japan Union Hospital Affiliated to \\ Jilin University, Changchun, Jilin 130031; ${ }^{3}$ Department of Pathology, Nanjing Drum Tower Hospital Affiliated to \\ Medical School of Nanjing University, Nanjing, Jiangsu 210008, P.R. China
}

Received April 3, 2017; Accepted December 22, 2017

DOI: $10.3892 / 01.2018 .7753$

\begin{abstract}
The present study aimed to investigate the clinicopathological features of primary intravascular large B-cell lymphoma (IVLBCL) of the lung. The clinical and histopathological data of three patients, and the literature was reviewed. The Ethics Committees of Drum Tower Hospital approved the current study based on the three cases. Fever and respiratory symptoms were the main presenting symptoms. Serum lactate dehydrogenase and C-reactive protein were significantly increased. Diffuse ground glass opacities or nodular consolidations were seen on high resolution computed tomography. Lung biopsy revealed lymphoma cells in the lumen of small blood vessels. Tumor cells expressed cluster of differentiation 20 and melanoma associated antigen (mutated) 1. Primary pulmonary IVLBCL is extremely rare and its prognosis is poor. Full recognition of its clinical character and improvement of the diagnostic awareness may help to reduce missed diagnosis, and facilitate appropriate treatment.
\end{abstract}

\section{Introduction}

Intravascular large B-cell lymphoma (IVLBCL) is a rare subtype of diffuse large B-cell lymphoma (LBCL) with a distinct intravascular proliferation of clonal lymphocytes. The incidence in males is slightly higher than that for females. Patients with IVLBCL usually have no lymphadenopathy, but tumor cells invade the blood vessels of multiple organs, such as the bone marrow, central nervous system, skin, lungs,

Correspondence to: Dr Hourong Cai, Department of Respiratory Diseases, Nanjing Drum Tower Hospital Affiliated to Medical School of Nanjing University, 321 Zhongshan Road, Nanjing, Jiangsu 210008, P.R. China

E-mail: 834895167@qq.com

${ }^{*}$ Contributed equally

Key words: intravascular lymphoma, large B-cell, lung liver, kidneys, and intestinal tract (1). Therefore, the clinical presentation is highly variable. Diagnosis of IVLBCL depends on histopathology, and can be challenging to diagnose due to the variable clinical manifestations, low incidence and diagnostic awareness deficiency.

IVLBCL is typically treated with chemotherapy including a chimeric anti-CD20 monoclonal antibody (most commonly rituximab), which has been reported to achieve a relatively good response (2), and autologous stem cell transplantation can also lead to good outcomes (3). Here, we report three cases of primary pulmonary IVLBCL diagnosed in our unit from 2010 to 2015. Also, we review the intravascular large B-cell lymphoma (IVLBCL) based on these cases and previous reports. The Ethics Committees of Drum Tower Hospital approved the current study based on the three cases.

\section{Case report}

Case 1. A 68-year-old male patient was admitted to the respiratory unit of our hospital with a 3-month history of progressive dyspnea on exertion, dry cough, intermittent high fevers to $39^{\circ} \mathrm{C}$, and weight loss. He had been treated with various courses of antibiotics without improvement. He had a 20-year history of diabetes mellitus, but no history of lung disease or smoking. The vital signs and physical examination were normal, except for a temperature $\left(38.3^{\circ} \mathrm{C}\right)$.

Blood tests revealed pancytopenia, with an elevated lactate dehydrogenase, $\beta_{2}-\mathrm{MG}$, and erythrocyte sedimentation rate; also, EBV-DNA copies level exceeded the normal level, which was $5.69 \times 10^{3}(\mathrm{IU} / \mathrm{ml})$.

High resolution computed tomography (HRCT) revealed thickened interlobular septa, multiple nodules and patchy ground glass opacities bilaterally (Fig. 1). A bone marrow biopsy showed diminution of hematopoietic cells, and megakaryocytes were not identified. Transbronchial lung biopsy (TBLB) revealed a small amount of atypical cells in the alveolar interstitium, but there was not sufficient pathologic change to establish a diagnosis. An open lung biopsy was performed, revealing a primary pulmonary lymphoma, diffuse large B-cell, non-germinal center origin. Immunohistochemical stains demonstrated that the cells were immunoreactive for 
for CD20 and Mum-1, and negative for CD3, CD10, CK, BCL-6 and MPO. The expression of CD4, CD3, CD5, CD8, $\mathrm{CD} 38, \mathrm{CD} 7$ and $\mathrm{CD} 2$ on the large cells was detected by flow cytometry. Clonal rearrangements of $\operatorname{Ig} \kappa-\mathrm{VJ}$ and $\operatorname{Ig} \kappa-\mathrm{V} / \mathrm{in}$ were detected by PCR (Fig. 2), without IGH/BCL2, BCL6, c-MYC fragmantation and P53 deletion. The patient treated with rituximab, cyclophosphamide, pirarubicin, vincristine, and prednisone [R-CHOP]. However, during the initial infusion of rituximab, anaphylacitc shock occurred. Treatment was changed from [R-CHOP] to [CHOP]. Complete remission (CR) was observed following 4 cycles of treatment, as visualized by $\mathrm{CT}$ scan (Fig. 3). Then the patient subsequently received two cycles of [CHOP] consolidation chemotherapy. One year later, the patient was readmitted with a relapse. Four cycles of [CHOP] regimen were administered followed by ifosfamide, carboplatin, and etoposide [ICE]. But only partial remission was achieved. He died from infection secondary to myelosuppression 1 year later.

Case 2. A 60-year-old female patient was admitted to the respiratory unit with a 1-month history of progressive dyspnea, and 20 days of intermittent high fever. The temperature fluctuated between 38 and $39^{\circ} \mathrm{C}$. She had been treated wide-spectrum antibiotics and indomethacin, but dyspnea and fever did not resolve. Her past medical history included a renal cyst and hysterectomy, but no lung disease. She was a non-smoker. On examination, anemia, fever and tachypnea were found.

Laboratory investigation Following diagnosis, the patient returned home for treatment, and she received cyclophosphamide, pirarubicin, vincristine, and prednisone [CHOP]. revealed a mild anemia, elevated LDH and ESR (Table I).

HRCT revealed diffuse centrilobular nodules and GGO bilaterally, and predominantly in the middle and upper lung. In the upper lung, thickened interlobular septa can also be seen (Fig. 4).

TBLB showed that CD20 positive atypical lymphocytes in the capillaries of the lung. Immunohistochemical stains demonstrated that these cells were immunoreactive to CD20, $20 \%$ positive for Ki-67 and negative for CD3 and CK (Fig. 5). The features were consistent with IVLBCL.

At first it seemed that treatment was effective and dyspnea improved. But she died quickly due to severe, concomitant infection.

Case 3. A 69-year-old female was admitted with a 2-month history of productive cough, exertional dyspnea, and one week of fever. The temperature fluctuated between 37.3 and $37.8^{\circ} \mathrm{C}$. She was managed with antitussives, expectorants, and bronchodilators, and antibiotics without improvement. In the past history, she had a cholecystectomy. She was a non-smoker. On examination she was found to have lip cyanosis, swollen feet, and an elevated temperature $\left(39.2^{\circ} \mathrm{C}\right)$.

Her laboratory investigation findings are shown in Table I. In brief, LDH and ESR were both elevated significantly besides moderate anemia. A HRCT of the chest revealed patchy GGO in bothlungs, with isolated thickening of interlobularsepta(Fig.6).A TBLB showed atypical lymphocytes in the vascular system of the lung. Immunohistochemical stains demonstrated that these cells were positive for CD20, CD79a, Mum-1, and LCA, but negative

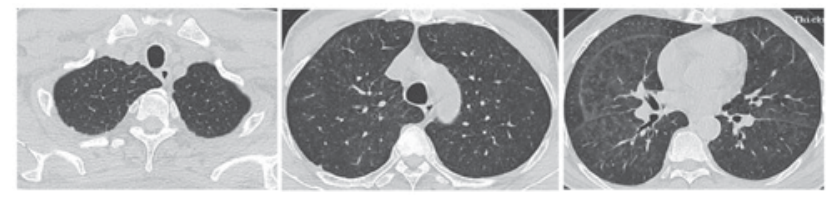

Figure 1. Computed tomography scan showed thickened interlobular septa, multiple micronodules and ground glass opacity patched in bilateral lungs. All the changed were a little slight, which needed reading carefully.
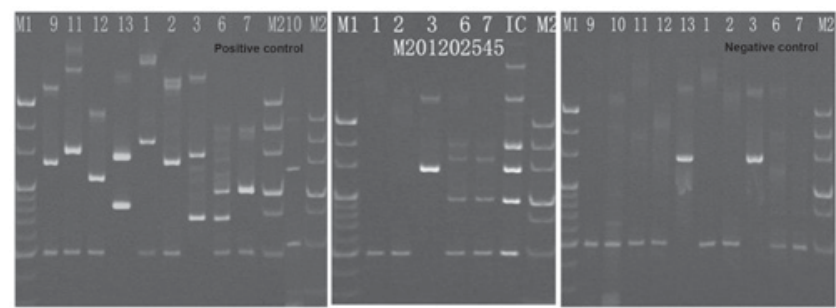

Figure 2. Clonal rearrangements of $\operatorname{Ig} \kappa-\mathrm{VJ}$ and $\operatorname{Ig} \kappa-\mathrm{V} /$ in were detected by PCR, IGH/BCL2, BCL6, c-MYC fragmantation and P53 deletion were negative. M1 and M2 representative markers, IC within the control sample.

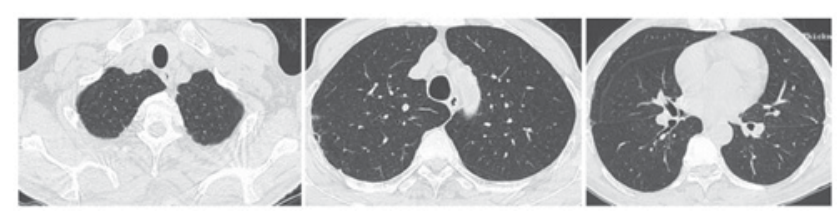

Figure 3. Computed tomography scan showed it was very clear in bilateral lungs.

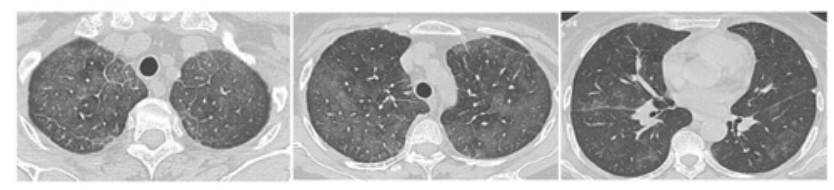

Figure 4. HRCT showed diffuse centrilobular nodules and ground glass opacity in the bilateral lungs, with local thinckened interlobular septa.

A

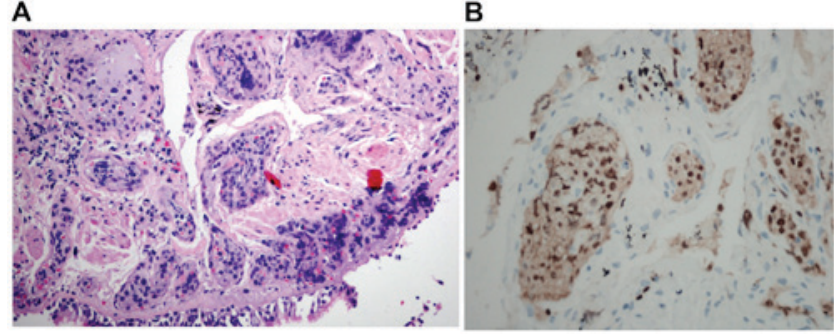

Figure 5. (A) Large atypical lymphoid cells within the small vessels of bronchial mucosa and sub-mucosa (H\&E, original magnification $\mathrm{x} 200$ ). (B) Strongly positive CD20 immunostaining of the same cells (original magnification $\times 200$ ).

for CD3, CD5, CD7, CD56, CD10, CK, TTF1, CD3e, EBER and MPO (Fig. 7).

Following diagnosis, she returned home and received chemotherapy with [CHOP] regimen. Then she was lost to follow-up. 
Table I. Pertinent laboratory data at the time of the patient's initial evaluation.

\begin{tabular}{|c|c|c|c|c|}
\hline \multirow[b]{2}{*}{ Variable } & \multicolumn{3}{|c|}{ Admission value } & \multirow{2}{*}{$\begin{array}{l}\text { Reference } \\
\text { range }\end{array}$} \\
\hline & CASE 1 & CASE 2 & CASE 3 & \\
\hline WBC $\left(\times 10^{9} / 1\right)$ & 3.0 & 6.1 & 4.5 & $4-10$ \\
\hline $\mathrm{Hb}(\mathrm{g} / \mathrm{l})$ & 79 & 90 & 87 & $130-175$ \\
\hline $\operatorname{PLT}\left(\times 10^{9} / 1\right)$ & 90 & 102 & 107 & $100-300$ \\
\hline $\mathrm{ESR}(\mathrm{mm} / \mathrm{hr})$ & 106 & 80 & 97 & $2-15$ \\
\hline B2-MG (mg/l) & 8.15 & $\begin{array}{c}\text { Not } \\
\text { checked }\end{array}$ & $\begin{array}{c}\text { Not } \\
\text { checked }\end{array}$ & $1.09-2.53$ \\
\hline LDH (IU/l) & 2,340 & 1,434 & 1,095 & $85-250$ \\
\hline ALB (g/l) & 28.7 & 29.2 & 31 & $32-55$ \\
\hline AST (IU/l) & 37.3 & 29.5 & 40 & $10-42$ \\
\hline ALT (IU/l) & 28 & 17.1 & 36 & $10-40$ \\
\hline BUN (mmol/l) & 6.7 & 5.3 & 3.7 & $2.85-7.14$ \\
\hline CREA (umol/l) & 81 & 75 & 46.6 & $53-115$ \\
\hline EBV-DNA (IU/ml) & $5.69 \times 10^{3}$ & Negative & $\begin{array}{c}\text { Not } \\
\text { checked }\end{array}$ & $<5.0 \times 10^{2}$ \\
\hline CRP (mg/l) & 13.4 & 79.9 & 88.5 & $0-8$ \\
\hline
\end{tabular}

WBC, white blood cell; $\mathrm{Hb}$, hemoglobin; Plt, platelet; ESR, erythrocyte sedimentation rate; B2-MG, B2-microglobulin; LDH, Lactic dehydrogenase; ALB, albmin; AST, Glutamic oxalacetic transaminase; ALT, Glutamic pyruvic transaminase; BUN, Urea nitrogen; CREA, creatinine; EBV-DNA, Epstein-Barr virus-deoxyribonucleic acid; CRP, $\mathrm{C}$ reactive protein.

Table II. Lung function and blood gas analysis.

\begin{tabular}{|c|c|c|c|c|}
\hline Variable & CASE 1 & CASE 2 & CASE 3 & Reference range \\
\hline $\mathrm{FVC} /$ pred $(\%)$ & 91.4 & 65 & 62.7 & $>80$ \\
\hline DLCO/pred (\%) & 80 & 38.3 & 43.2 & $>80$ \\
\hline $\mathrm{PaO}_{2}(\mathrm{mmHg})$ & 61 & 62 & 48 & $80-100$ \\
\hline $\mathrm{PaCO}_{2}(\mathrm{mmHg})$ & 32.2 & 32 & 29.5 & $35-45$ \\
\hline
\end{tabular}

FVC/pred, forced vital capacity/percent predicted; DLCO/pred, carbon monoxide diffusing capacity/percent predicted; $\mathrm{PaO}_{2}$, oxygen partial pressure; $\mathrm{PaCO}_{2}$, partial pressure of carbon dioxide.

\section{Discussion}

In 1958, Pfleger and Tappeiner first described IVLBCL. After that, cases of IVLBCL were reported in succession. In 2008, the WHO classified it as a rare, specific type of non-Hodgkins lymphoma (NHL). IVLBCL typically occurs in elderly patients with male to female ratio of 1.3 to 1 . The main feature of this type of lymphoma is that it is a diffuse, occlusive proliferation in vessels, especially in the capillaries, small arteries and veins (4). Previously, about 50\% cases were diagnosed by post-mortem. Now, with the development of immunohistochemical and monoclonal antibodies, and a greater clinical awareness, establishing the diagnosis of this

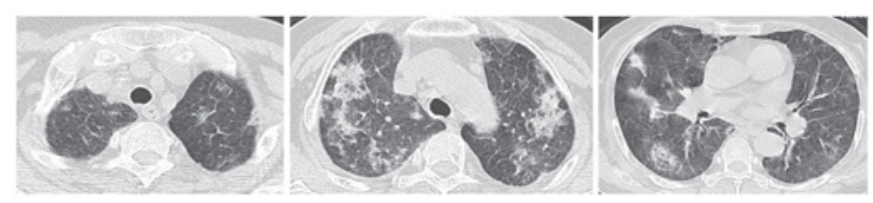

Figure 6. HRCT showed multiple patches, and ground-glass opacity in bilateral lungs, with local interlobular septal thickening.

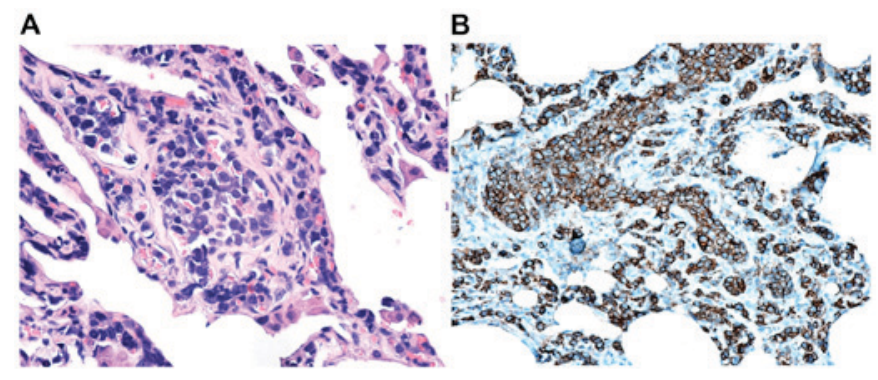

Figure 7. (A) Large atypical lymphoid cells within the interalveolar septal capillaries (H\&E, original magnification x400). (B) Strongly positive CD20 immunostaining of the same cells (original magnification x200).

disease during lifetime, similar to our cases, is believed to be increasing (5).

The clinical manifestations of IVLBCL include both constitutional symptoms, such as fever, weight loss, night sweats, and general fatigue, and organ-specific symptoms due to tumor cells infiltrating the vessels of any organ. The heterogeneous and nonspecific symptoms make identification of this disease in patients challenging. Laboratory findings suggestive of IVLBCL or other lymphoproliferative diseases include elevation of the C-reactive protein (CRP), LDH, $\beta_{2}$-MG, interleukin-2R (IL-2R) or serum albumin. Close correlation between increased LDH level and the differentiation of tumor cells has been reported (6-8).

When lungs are involved by IVLBCL, the clinical manifestations include cough, sputum production, and dyspnea. Some patients also present with hypoxemia, hypercalcemia, pulmonary embolism, pulmonary hypertension or hemophagocytic syndrome (9-11). Lung function frequently shows impaired lung volumes or diffusion capacity (12). The appearance of lungs on HRCT is varied, with findings including centrilobular nodules, interlobular septal thickening, and GGO. Interstitial shadows and thickening of bronchovascular bundles usually suggest haematological and/or lymphatic spread (12).

Recently, ${ }^{18} \mathrm{~F}$-FDG PET/CT has emerged as a powerful imaging modality in the assessment, diagnosis, staging and treatment response in lymphoma (13). When respiratory symptoms suggest pulmonary involvement without abnormal performance in lung HRCT scan, FDG-PET/CT can be a useful tool for the early diagnosis of IVLBCL $(13,14)$.

All of our cases had fever, dyspnea, hypoxaemia, anemia, increased LDH and an elevated ESR levels. Two of the three patients had increased level of CRP. These clues suggested to us that these patients may have had some kind of lymphoproliferative diseases. Besides, HRCT showed GGO, nodules, and thickened interlobular septa bilaterally in the lungs, which denoted us that the disease may spread 
along lymphatic structures. Two of the three had ventilation impairment and diffusion abnormalities (Table II). The radiological characteristics and pulmonary function characteristics are similar to those seen in interstitial lung diseases (ILD). Therefore, histopathologic analysis is required to make diagnosis.

The histopathology of IVLBCL shows large malignant lymphocytes filling small vascular lumina. In addition, the bone marrow seems to be the most relevant diagnostic site for Asian patients (5).

Regarding pulmonary investigations, an open lung biopsy or a trans-thoracoscopy lung biopsy is the most powerful method for diagnosis. Sometimes TBLB may also be useful, especially in patients with abnormal HRCT features (15). For our patients, two of them (CASE 2 and 3) were diagnosed by TBLB. In addition, when the pathology of CASE 1 was re-reviewed following diagnosis by open lung biopsy, we found that we could set up the same diagnosis by TBLB. The diagnosis was missed at first, because this disease was not considered at that time. However, the bone marrow biopsy was unremarkable in our case (CASE 1).

A timely and accurate diagnosis and the appropriate treatment can significantly improve the clinical outcomes. Currently there is no established treatment for IVLBCL because of the small number of cases. The treatment of cases with lung involvement is similar to that for diffuse LBCL, consisting of CHOP or CHOP-like regimens plus rituximab (CHOP-R or CHOP-like-R) and CNS prophylaxis (16-18).

As for the survival time, it was reported that the mean 3 -year overall survival was 33 months according to the report from Ferreri and coworkers (19).

Although IVLBCL and primary pulmonary IVLBCL are rare diseases, we have made a diagnosis and treated three patients during 5 years. After review of these cases, we conclude: 1. Rare diseases may be encountered in clinical work. 2. Since HRCT characteristics of primary pulmonary IVLBCL is similar to ILD, both diagnosis and differential diagnosis are very important. 3. TBLB can be useful for diagnosis, as shown in our cases.

\section{Acknowledgements}

The present study was supported by the National Natural Science Fund of China (grant no. 81570055). We thank Prof. Dr. Med. Ulrich Costabel (from Department of Pneumology/Allergology, Ruhrlandklinik, University Hospital, University Duisburg-Essen, Essen, Germany) and Associate Professor Paul John Wolters (from Department of Medicine, University of California, San Francisco, CA, USA) for article layout, logic sequential adjustment and text revision work. This abstract was presented at the American Thoracic Society 2017 International Conference, May 19-24, 2017 in Washington, DC, IL, USA and was published as abstract no. 6579 in American Journal of Respiratory and Critical Care Medicine 2017.

\section{References}

1. Ferreri AJ, Campo E, Seymour JF, Willemze R, Ilariucci F, Ambrosetti A, Zucca E, Rossi G, López-Guillermo A, Pavlovsky MA, et al: Intravascular lymphoma: Clinical presentation, natural history, management and prognostic factors in a series of 38 cases, with special emphasis on the 'cutaneous variant'. Br J Haematol 127: 173-183, 2004.

2. Ferreri AJ, Dognini GP, Govi S, Crocchiolo R, Bouzani M, Bollinger CR, D'Incan M, Delaporte E, Hamadani M, Jardin F, et al: Can rituximab change the usually dismal prognosis of patients with intravascular large B-cell lymphoma? J Clin Oncol 26: 5134-5136, 2008.

3. Sawamoto A, Narimatsu H, Suzuki T, Kurahashi S, Sugimoto T and Sugiura I: Long-term remission after autologous peripheral blood stem cell transplantation for relapsed intravascular lymphoma. Bone Marrow Transplant 37: 233-234, 2006.

4. Swerdlow SH, Campo E, Harris NL, Jaffe ES, Pileri SA, Stein H, Thiele J and Vardiman JW: WHO classification of tumours of haematopoietic and lymphoid tissue. Fourth Edition. Geneva, World Health Organization, 2008.

5. Mahasneh T, Harrington Z, Williamson J, Alkhawaja D, Duflou J and Shin JS: Intravascular large B-cell lymphoma complicated by invasive pulmonary aspergillosis: A rare presentation. Respirol Case Rep 2: 67-69, 2014.

6. Anila KR, Nair RA, Koshy SM and Jacob PM: Primary intravascular large B-cell lymphoma of pituitary. Indian J Pathol Microbiol 55: 549-551, 2012.

7. Ponzoni M and Ferreri AJ: Intravascular large B cell lymphoma: Widespread but not everywhere. Acta Haematol 131: 16-17, 2014.

8. Khalifa KA, Alkilani AA, Ismail $\mathrm{H}$ and Soliman MA: Evaluation of some biochemical markers as prognostic factors in malignant lymphoma. J Egypt Natl Canc Inst 20: 47-54, 2008.

9. Sinha N, Lantigua L, Niazi M and Diaz-Fuentes G: An elderly lady with fever of unknown etiology and severe pulmonary hypertension: Intravascular lymphoma-an elusive diagnosis. Case Rep Med 2013: 153798, 2013.

10. Chinen Y, Nakao M, Sugitani-Yamamoto M, Kiyota M, Horiike S, Kuroda J and Taniwaki M: Intravascular B-cell lymphoma with hypercalcemia as the initial presentation. Int J Hematol 94: 567-570, 2011.

11. Fung KM, Chakrabarty JH, Kern WF, Magharyous H, Gehrs BC and Li S: Intravascular large B-cell lymphoma with hemophagocytic syndrome (Asian variant) in a Caucasian patient. Int J Clin Exp Pathol 5: 448-454, 2012.

12. Yu H, Chen G, Zhang R and Jin X: Primary intravascular large B-cell lymphoma of lung: A report of one case and review. Diagn Pathol 7: 70, 2012.

13. Seam P, Juweid ME and Cheson BD: The role of FDG-PET scans in patients with lymphoma. Blood 110: 3507-3516, 2007.

14. Wagner T, Brechemier D, Dugert E, Le Guellec S, Julian A, Hitzel A and Beyne-Rauzy O: Diffuse pulmonary uptake on FDG-PET with normal CT diagnosed as intravascular large B-cell lymphoma: A case report and a discussion of the causes of diffuse FDG uptake in the lungs. Cancer Imaging 23: 7-12, 2012.

15. Nishizawa T, Saraya T, Ishii H and Goto H: Antemortem diagnosis with multiple random skin biopsies and transbronchial lung biopsy in a patient with intravascular large B-cell lymphoma, the so-called Asian variant lymphoma. BMJ Case Rep 2014: pii: bcr2013202661, 2014

16. Chen Y, Ding C, Lin Q, Yang K, Li Y and Chen S: Primary intravascular large B-cell lymphoma of the lung: A review and case report. J Thorac Dis 6: E242-E245, 2014.

17. Takahashi H, Tomita N, Yokoyama M, Tsunoda S, Yano T, Murayama K, Hashimoto C, Tamura K, Sato K and Ishigatsubo Y: Prognostic impact of extranodal involvement in diffuse large B-cell lymphoma in the rituximab era. Cancer 118: 4166-4172, 2012.

18. Shimada K, Matsue K, Yamamoto K, Murase T, Ichikawa N, Okamoto M, Niitsu N, Kosugi H, Tsukamoto N, Miwa H, et al: Retrospective analysis of intravascular large B-cell lymphoma treated with rituximab-containing chemotherapy as reported by the IVL study group in Japan. J Clin Oncol 26: 3189-3195, 2008.

19. Ferreri AJ, Campo E, Ambrosetti A, Ilariucci F, Seymour JF, Willemze R, Arrigoni G, Rossi G, López-Guillermo A, Berti E, et al: Anthracycline-based chemotherapy as primary treatment for intravascular lymphoma. Ann Oncol 15: 1215-1221, 2004. 